\title{
PSICANÁLISE, POLÍTICA E VERDADE ${ }^{1}$
}

Entrevista com Tales Ab'Sáber

\author{
Psychoanalysis, Politics and Truth
}

Tales Ab'Sáber ${ }^{2}$

Universidade Federal de São Paulo - UNIFESP

\begin{abstract}
RESUMO: Nesta entrevista, o psicanalista e professor Tales Ab'Sáber reflete sobre a disputa pela 'verdade' histórica e as formas como diferentes sujeitos e para diferentes fins dela se apropriam, mobilizando-a para fins políticos eleitorais. Inicialmente, aborda um desses usos, discutindo o revisionismo histórico e sua relação com o fascismo. Em seguida, apresenta as contribuições que campos científicos e reflexivos como a Psicanálise podem fornecer para lidarmos com o atual contexto político brasileiro, em que o revisionismo e o fascismo gracejam no modus-operandi da extrema-direita antidemocrática, violenta, que põe em marcha um discurso de ódio, tal como ele e dois outros colegas tão bem retrataram no documentário Intervenção: amor não quer dizer grande coisa (2017), produzido por eles a partir de vídeos na web que circularam em 2016, ano do golpe, em que representantes dessa extrema-direita convocavam a população para pedir nas ruas "uma intervenção militar" imediata.
\end{abstract}

Palavras-chave: Verdade; Política; Revisionismo histórico; Fascismo; Psicanálise.

ABSTRACT: In this interview, the psychoanalyst and professor Tales Ab'Sáber reflects on the dispute over historical 'truth' and the ways in which different subjects and for different purposes are appropriated, mobilizing it for electoral political purposes. Initially, he addresses one of these uses, discussing about historical revisionism and fascism. Then he presents the contributions that scientific and reflective fields such as Psychoanalysis can provide to deal with the current Brazilian political context in which revisionism and fascism joke in the modus-operandi of the anti-democratic, violent extreme right, which sets in motion a discourse of hate, as he and two other colleagues portrayed so well in the documentary Intervention: love doesn't mean much (2017), produced by them

\footnotetext{
${ }^{1}$ Entrevista realizada no dia 12 de setembro de 2018, durante o V CIAD - Colóquio Internacional de Análise do Discurso: Discurso e (pós)verdade. Efeitos de real e sentidos da convicção. Na ocasião, o entrevistado proferiu a conferência "Ilusão, Convicção e Mentira: a psicopolítica da pós-verdade". A equipe responsável pela produção, transcrição, retextualização e revisão desta entrevista foi composta por Ana Cecília Cava, Bianca Lopes, Éder Coimbra, Emily Silva, Leonardo Henrique Breda, Maria Carolina Coradini, Paula Zangrossi, Pedro Henrique Turcie Stephani Izidro, discentes do curso de bacharelado em Linguística da UFSCar, e por Luzmara Curcino, docente no Departamento de Letras e no Programa de Pós-graduação em Linguística da Universidade Federal de São Carlos (DL/PPGL/UFSCar). Contribuíram no apoio técnico Pedro Varoni, Andrêi Krasnoschecoff, Caio Carniel, Daniel P. Graciano e Livia Beatriz Damaceno. Esta entrevista, em sua versão audiovisual, está disponível em: <http://www.observatoriodaimprensa.com.br/tag/tales-absaber/>.

${ }^{2}$ Professor de Filosofia da Psicanálise no curso de Filosofia da Universidade Federal de São Paulo - UNIFESP e membro do Departamento de Psicanálise do Instituto Sedes Sapientiae. Entre suas principais publicações, destacamos os livros Lulismo, carisma pop e cultura anticrítica (2011); Dilma Rousseff e o ódio político (2015); e Michel Temer e o fascismo comum (2018); entre outros. Mais recentemente, coproduziu o documentário Intervenção: amor não quer dizer grande coisa (2017).
} 
from videos on the web that circulated in 2016, the year of the impeachment, in which representatives from that extreme right called on the population to ask for "immediate military intervention" on the streets.

Keywords: Truth; Politics; Historical revisionism; Fascism; Psychoanalysis. 


\section{Fascismo, Revisionismo histórico e Verdade}

Entrevistadores: $\mathrm{Na}$ atualidade, que alguns nomeiam como era da 'pós-verdade', em um contexto tecnológico e político que amplia a difusão de mentiras como se fossem verdades (as ditas 'fake news'), poderíamos dizer que vivemos uma crise no que diz respeito à nossa percepção ou concepção da verdade?

Tales Ab'Sáber: Esta é uma pergunta muito profunda sobre o que é 'verdade' nesta situação em que vivemos de uma espécie de estrutura social que permite a produção de uma multiplicação de discursos - grande parte deles atacando referências históricas compartilhadas. Portanto, são discursos interessados que tentam intervir politicamente, são discursos de ação política, que não necessariamente se apresentam como tais, e que por isso nos colocam uma questão profunda acerca do conceito da'verdade': a'verdade’ não estaria, portanto, no conteúdo do que é enunciado e mostrado. Ela se encontraria no resultado político dessas ações, o que por princípio é legítimo. Vivemos uma espécie de "os fins justificam os meios" pós-moderno e industrial. O que moveria esses discursos é o resultado de um ganho político, e não o seu lastro relativo àquilo que chamávamos de 'verdade'.

Podemos nos perguntar: mas o que é a 'verdade'? A verdade é uma narrativa acordada. Ela corresponde a certos consensos estabelecidos sobre o sentido da História. A História é isso. Ela resulta de um consenso sobre as marcas do passado que importam. Essa sua condição permite que voltemos sobre essa narrativa e que possamos rever o que foi acordado, compreender as condições de sua produção e os posicionamentos que nortearam o que foi enunciado. No entanto, para isso, há uma série de procedimentos e formas institucionais de controle para a aproximação dessas narrativas da verdade do passado. O que esses movimentos contemporâneos têm feito é negar, simplesmente, os fundamentos que dão lastro de verdade a essas narrativas. Eles o fazem não porque tenham um projeto superior, mais adequado para isso, mas porque têm um projeto de poder imediato e sectário.

A ideia neoconservadora, que foi gestada de início nos Estado Unidos, é a de questionar as bases, rever e romper o pacto social estabelecido por acordos progressistas e democráticos empreendidos no passado, pois, segundo os movimentos que defendem essa ideia, esse pacto teria sido inteiramente construído pela esquerda. Não importa para eles que esses acordos correspondam hoje a toda uma tessitura da cultura, portanto, a toda uma leitura da História que civiliza as relações sociais. Essas ações de poder se constituem por esses discursos de não-verdade, também chamados de 'pós-verdade' ou de 'fake news', e que na 
verdade não são nada mais do que a velha 'mentira'. Na medida em que esses dizeres não têm lastro, eles são mentiras ideologicamente interessadas, são jogos de linguagem de interesse. Poderíamos dizer que o que testemunhamos neste momento é um grande revisionismo histórico.

O revisionismo sempre existiu. O revisionismo em relação à história do Nazismo, por exemplo, é bastante conhecido e se mostra claramente como um posicionamento interessado. Se observarmos quem são seus enunciadores, veremos que são personagens culturais degradados, de extrema-direita, afirmando que não existiram os crimes do Nazismo. Isso não é nada mais do que uma mentira pública. E, como tal, não é difícil ser desmascarada, porque nós temos instrumentos, dispositivos culturais e sociais para controlar a produção dessas mentiras. Nós dispomos de relatos, de provas, de historiadores, de universidades, ou seja, de toda uma institucionalidade que permite que essas mentiras sejam percebidas como mentiras. O que tem acontecido nos últimos tempos, e que é novo, é que o revisionismo tem ganhado espaço na cultura, tem aberto todo um continente. Ele joga com a inversão das lógicas e coloca as próprias instituições, que tradicionalmente desenvolveram meios e são as responsáveis pelas medidas de controle e de checagem do valor de verdade do que circula, sob o regime da mentira. Segundo o revisionismo, a mentira se torna a verdade, e as instituições que trabalhariam para a certificação e localização da verdade são então declaradas como as produtoras da mentira.

Um retrato disso é o que se vê hoje, nos Estados Unidos, quando o presidente Donald Trump diz que o The New York Times é produtor de fake news ${ }^{3}$. Vejamos: um conhecido produtor de mentira política, sem nenhum lastro histórico quanto à 'verdade' do que afirma, refere-se ao jornalismo oficial, tradicional, como instituição produtora de mentira. É claro que o The New York Times é uma instituição ideológica e com posicionamentos específicos, mas não se pode perder de vista que se trata de uma instituição histórica densa, checada, as pessoas sabem o que ela é. De maneira correlata, é o que se vive no Brasil em relação às universidades. A direita revisionista, que pretende dissolver todo um sistema de controles simbólicos de suas próprias ações, diz que as universidades são falseadoras, são produtoras de mentiras. Trata-se, portanto, claramente de um embate institucional de poderes. As práticas próprias desses grupos que constituem os contornos desse tempo e desse funcionamento

\footnotetext{
${ }^{3}$ Trump publicou em seu twitter, em 2018, o "Prêmio Fake News" e divulgou uma lista do que considera serem os 10 maiores produtores de mentiras em relação a seu governo. Entre nomes de jornalistas e de instituições, a lista é composta dos principais jornais e redes de notícias, como The New York Times, The Washington Post e CNN. Disponível em: <https://g1.globo.com/pop-arte/noticia/trump-da-premio-fake-news-a-vencedor-do-nobelcnn-e-ny-times.ghtml>.
} 
nomeado como 'pós-verdade' se mostram essencialmente como estratégias de um jogo político de interesses, jogo que está tentando alterar a estrutura da trama simbólica há muito acordada.

A especificidade contemporânea é a existência de instrumentos novos mobilizados nesse jogo, ligados tanto à vida cotidiana - com a possibilidade das pessoas se expressarem nas redes diretamente, desnorteadas pela crise do capitalismo contemporâneo que reforça a emergência de posturas arcaicas, de tipo fascista e revisionista - quanto à tomada de poder com base em um projeto ultra neoliberal, que tem por objetivo comum atacar as medidas de controle da verdade.

É preciso compreender que ao falarmos da verdade, da verdade da História, nós estamos discutindo acerca do sentido da História, ou seja, acerca da orientação e do valor da experiência histórica. Não se pode cair em uma metafísica do tipo platônica, segundo a qual existiria a verdade em si mesma e é a verdade pura que nos moveria. Não é disso que se trata. A pergunta que é preciso fazer é: que compromisso, que responsabilidade aquele que conta a História deve ter? Não é o caso de se relativizar a verdade, tal como se deu em uma leitura pós-moderna. É preciso, na verdade, compreender que essas tecnologias mobilizadas em prol do revisionismo histórico e as violências simbólicas que esse revisionismo autoriza visam relativizar o compromisso com a verdade da posição que tem legitimidade para enunciar a História. Estamos diante de um questionamento da História. Toda uma filosofia da História se encontra em jogo, quando ela é transformada apenas em conjuntos ou circuitos de narrativas, todas equivalentes, todas mais ou menos intercambiáveis, tal como afirmou o 'pósmodernismo'. Segundo essa perspectiva, a cultura é apenas uma luta por uma narrativa qualquer. Se a cultura é apenas uma luta de força direta entre posicionamentos distintos, quem tem mais força tem o poder de dizer o que a coisa é. Nessa visão, a História resultaria meramente de uma disputa pela verdade e equivaleria ao espaço da narrativa dos vencedores. O resultado adviria da lógica: quem vence conta a sua'verdade'.

Os nazistas, por exemplo, pensavam dessa forma. Se vencessem a guerra, suas práticas de crimes hediondos contra a humanidade não existiriam, uma vez que não haveria quem os relatasse. Ela seria contada como uma história de emanação do poder, mesmo que suas marcas não constassem com o lastro da verdade. Por isso, segundo essa visão, importa para o poder enunciar a História. 
Faz muito sentido neste momento nos voltarmos para o que disse o importante filósofo Walter Benjamin em suas Teses ${ }^{4}$ filosóficas sobre a História. Uma de suas grandes questões era exatamente essa: o que confere verdade a uma enunciação da História, a não ser que seja uma enunciação vinda do poder? E a resposta dele é: a verdade, para um narrador da História que não faça parte do poder, se encontra em seu posicionamento contra a violência da história, em seu compromisso com os violentados e com os sacrificados da história. Essa deve ser a verdade da História. A luta que hoje vemos não é pelo dizer verdadeiro que a história dos vencedores quer negar, mas sim a luta do poder dizer o que é a verdade, como um ato do poder. Na disputa sobre o que é a verdade, são esses dois campos que estão se digladiando. Nós, que somos da universidade, que nos dedicamos a refletir sobre a cultura e sobre a história, nós temos de saber como nos posicionar nessa tempestade que o poder quer provocar ao dissolver a ideia de que há uma verdade na História.

Qual é, então, a verdade da História? A verdade da História é a verdade da violência, é a verdade da crítica ao poder. É exatamente isso que se pretende dissolver. A questão que é nova hoje é a existência desses grandes mecanismos de poder para a produção dessa onda gigantesca de revisionismo e dissolução dos compromissos com a História. Ao passar por uma nova ordem tecnológica, tem-se um outro elemento. Além do poder desejando contar a História a seu modo, para o seu próprio incensamento e aumento de seu próprio poder, tem-se uma questão psíquica, da Psicanálise, que pode ser formulada nos seguintes termos:"Por que as pessoas desejam a violência e aderem ao poder?”.

É esse nível da tempestade de produção de notícias falsas o que tem chocado as pessoas. Aqui há algo muito interessante. No mundo das notícias falsas, se alguém não se identifica com a produção da falsificação da História, é porque dispõe de uma percepção acerca da linguagem, de uma compreensão dos contextos, de uma leitura dos processos históricos de modo a saber que esse personagem não casa com essa ação, que por sua vez não casa com esse outro personagem. De fato, quando analisamos algumas dessas notícias falsas, é muito notável, é muito perceptível o que é falso, o que se pode constatar por meio da observação de sua estrutura característica. São narrativas em que as notícias falsas interessadamente têm uma excitação espetacular.

A notícia falsa não é, na verdade, uma notícia. É uma propaganda. É uma propaganda negativa. Se pensássemos assim, talvez conseguíssemos instrumentos para criticar e reconhecer onde se tem esse desejo de falsificação. Mas isso é algo muito complexo. A

\footnotetext{
${ }^{4}$ Cf. Benjamin (1987).
} 
exemplo disso, o atual presidente dos Estados Unidos, Donald Trump, em um esquema ilegal, contratou robôs russos para produzir notícias falsas, ou seja, a produção de notícias falsas com a finalidade de intervir na política faz parte de uma máquina industrial global. Ao mesmo tempo, nós estamos aqui, na universidade, conversando, suscitando esse tipo de reflexão como uma tentativa de reagir a isso. É assim.

\section{Psicanálise e Política hoje}

Entrevistadores: Em que medida a Psicanálise pode contribuir para lidarmos com o momento político atual?

Tales Ab'Sáber: A psicanálise é algo muito bonito e muito radical. Ela enuncia uma aproximação do sentido, que nunca se completa, da ideia do 'inconsciente'. O inconsciente, por sua vez, é uma criação freudiana a partir de determinados elementos concretos dos discursos, da experiência emocional, da vida. Sigmund Freud pressupõe a existência do inconsciente e este inconsciente freudiano tem um modo de ser organizado. Ele é uma estrutura de defesas, portanto, é uma estrutura de conflitos, cuja solução desses conflitos é a abertura do espaço do inconsciente. Essa abertura, por sua vez, também é produtora de ações psíquicas, porque há um sujeito do inconsciente, uma estruturação em que o inconsciente é ativo na produção dessas ações.

A Psicanálise tem em seu coração um enigma, uma ausência, uma lacuna. Ela é o contrário da ideologia, no sentido de que a ideologia 'sabe' e satura com verdade falsa o que é o sentido das coisas. A Psicanálise é uma experiência de aproximação do sentido que nunca se completa. É nesse sentido que ela é muito radical. Ela tem esse caráter dito 'clínico', externo, que é uma relação com esse sujeito ausente e presente, paradoxal, que é o inconsciente.

O que psicanalistas contemporâneos têm percebido é que existe uma vida social do inconsciente. Freud já havia estabelecido isso em seus textos dos anos 20, todos ligados à relação do inconsciente com a cultura. Três textos são muito importantes. Um deles intitula-se Psicologia das massas e análise do Eu (1921), no qual aborda a regressão psíquica dos sujeitos uma vez em grupos, quando eles criam uma espécie de psiquismo grupal que diminui a racionalidade individual. Freud apresenta uma interpretação dessa formação de grupos que agem simbolicamente, mas não pensam. Hoje, nós estamos vendo isso ocorrer com muita clareza. Esses grupos de direita, de fascistas, agem simbolicamente, mas não pensam. Eles 
não trabalham com o pensamento, com a história, com balizas comuns. Se soubessem reconhecer, diriam: "Não consideramos o outro tão verdadeiro como interlocutor como eu". Se assim o fizessem, seria uma postura dialética, dialógica, o que não fazem, não sabem fazer de modo algum. Eles trabalham visando um poder, e de modo agentivo e com o desejo direto, sem freios. Freud estuda isso, exatamente a formação desse psiquismo coletivo regressivo nesse texto que mencionei.

Os outros dois textos sobre essa relação do inconsciente com a cultura são $O$ mal-estar na Civilização (1930), sobre o papel da cultura nessa estruturação do inconsciente, sobre sua ação de controle das pulsões individuais, sendo assim geradora de mal-estar. Em O futuro de uma ilusão (1927), ele aborda o lugar da religião, não apenas como instituição estruturada, mas como pensamento religioso, como pensamento mágico, mítico. Do ponto de vista psicanalítico, essa 'fé' político-abstrata do fascismo tem a mesma estrutura da religião. Ela não corresponde aos fatos, não corresponde ao outro, ela é o que se deseja que seja, não em relação ao que seria um futuro pós-morte, o que seria próprio da religião, mas em relação ao futuro da vida social. Os fascistas têm um projeto reduzido, simplificado, mas para eles muito intenso, de sociedade, projeto em geral voltado para o passado, de restauração de um passado e de adesão ao estágio atual do poder. Freud, portanto, já trabalhava muito com essas questões da relação entre esse sujeito do inconsciente e a cultura, portanto, desse sujeito do inconsciente e a política.

Muitos psicanalistas contemporâneos se perguntam, a partir das dinâmicas psicanalíticas, o sentido de certas emergências históricas, de figuras que o processo histórico produz. Por exemplo, que elementos constroem uma experiência de fato, uma faticidade, no Brasil, do carisma político, do carisma de Lula? Essa é uma questão de grande interesse psicanalítico, e ao mesmo tempo político. O carisma é sabidamente uma forma de poder, de produção de poder, tal como Max Weber, na sociologia, já havia dito ${ }^{5}$. No entanto, o carisma é um enigma, sobre o qual os psicanalistas têm algo a dizer, com toda a complexidade dialética da Psicanálise. Se olharmos o carisma do Lula, podemos a partir dele constatar uma outra coisa, por exemplo a falta de carisma, de imaginação política, e mesmo de desejo político de um personagem rebaixado como Michel Temer. Ele é o oposto do Lula. Percebido isso, se pode assim também perceber dinâmicas subjacentes de sentido, que também fazem parte do poder e da ideologia. Eu sou um psicanalista que trabalha assim e meus trabalhos sobre política também se dão desta forma.

\footnotetext{
${ }^{5}$ A dominação carismática é um dos tipos de dominação legítima apontados por Max Weber no texto "Os três tipos de dominação legítima" em sua obra Economia e Sociedade (1956).
} 


\section{Política e antidemocracia na extrema-direita}

Entrevistadores: Como tem agido politicamente o setor da sociedade retratado em seu documentário Intervenção: amor não quer dizer grande coisa ${ }^{6}$, de 2017 ?

Tales Ab'Sáber: Na produção desse documentário pudemos testemunhar as ações e o tipo de discurso adotado por um grupo extremado, de extrema-direita, em geral ligados ao Exército, são ex-militares, ou próximos dos militares, da ativa ou da reserva. Registramos a presença desses grupos de extrema-direita em chats, canais da internet, que, como se convencionou chamar, fazem parte de uma 'bolha' da extrema-direita. É uma bolha identificatória, como dizem os analistas, em que as pessoas vão sendo engajadas nesse espaço e vão tomando uma mesma posição. As pessoas se identificam com a posição emocional dominante e com o modo de seus representantes de ler a realidade.

Como nós sabemos, esse grupo se viu frustrado em seu desejo e fracassou em sua proposta insistente de que os militares da ativa rompessem o pacto Democrático e retomassem o poder. Aqui eu usei a palavra retomar, e não a palavra tomar, porque há uma sólida tradição no Brasil, de viés bonapartista, salvacionista, militar, elitista, que ecoa ao longo do tempo a mesma percepção que agora é reiterada por esse grupo, a de que Democracia não funciona em um país como o Brasil, de que ela não é válida, e a de que para haver ordem nesse país, apenas com militares, uma vez que se trata de um país com um povo sem instrução, sem organização. Sem dúvida, somos um país com massas de população não formada, não integrada. O que não é dito por eles é que essa falta de formação advém de nossa formação escravocrata, desigual e injusta, e da permanência de uma elite que despreza o povo.

Segundo a perspectiva desse grupo, o Exército teria a função de mediador das elites num país em que a Democracia não funciona. Assim como dizia Sérgio Buarque de Holanda: “a Democracia no Brasil sempre foi um grande mal-entendido". Com base em afirmações como essa, a ideia de base dessa gente é que aqui a Democracia não tem validade, porque não se pode colocar o voto de um ignorante em pé de igualdade com o voto da elite, porque isso, para eles, é uma distorção da realidade. Essa é a postura basilar antidemocrática brasileira. Essas pessoas retomam, a seu gosto, esse efeito da 'formação do Brasil', das 'raízes do Brasil', como dizia Sérgio Buarque. Elas falam desse lugar, a partir desse efeito de sentido, e

\footnotetext{
${ }^{6}$ Esse documentário foi realizado em parceria com o cineasta Rubens Rewald, professor de dramaturgia e roteiro no curso de Cinema da ECA-USP, e com o jornalista livre Gustavo Aranda. Ele registra o que é enunciado via internet em chats de grupos da extrema-direita, de modo a apreender sua visão de mundo à época das manifestações por impeachment, em 2016.
} 
sonham com o Exército, o Exército que deu o golpe e proclamou a República, depois participou do Estado Novo getulista, em seguida derrubou esse Estado Novo e ainda forçou os golpes da Guerra Fria, que deu o golpe em 64, e que ameaçou realizar intervenções no Estado várias vezes. É com este Exército, que, por cerca de cem anos, participou ativamente do modo antidemocrático da vida pública e política brasileira, que a extrema-direita sonha, idealiza e deseja.

Esse grupo contava com essa tradição antidemocrática do Exército brasileiro e, para a sua surpresa, e de muitos outros, inclusive da esquerda, o Exército, de modo republicano e contemporâneo, se recusou a retrilhar novamente esse caminho e exercer esse papel. Essa é uma novidade importante do ponto de vista da cúpula do Exército, para o qual não é mais possível um ato de força externo ao jogo da Democracia. Essa possibilidade não existe mais. Constatar isso, não significa dizer que essa corporação seja muito progressista. Ela é, na verdade, institucionalmente garantista e, nesse sentido, em relação a esse arcaísmo, sua resposta foi progressista.

O filme mostra psiquicamente a produção dessa crise, da qual, em seu auge, a postura do Exército era a de "não responder a isso", o que inclusive desqualificava, deslegitimava esse discurso extremado à direita. Ali tínhamos, como diz Freud, uma "horda de identidade primitiva" em busca de um líder sem líder, na qual o líder simbólico se recusou a ocupar esse lugar.

Esse grupo teve duas funções importantes no processo subsequente ao do impeachment. Por um lado, foi muito importante na criação da violência simbólica, da política do ódio, que moveu a crise que levou ao impedimento da presidente Dilma Rousseff, ao golpe, de uma nova modalidade de golpe da Democracia. Por outro, eles forneceram o lastro de opinião pública e de legitimidade democrática ao golpe.

Em um primeiro momento, essas pessoas fizeram a tempestade do excesso, do ilimitado, das razões estratégicas em relação à esquerda, ou seja, do vale-tudo simbólico. O vale-tudo simbólico, sua energia, que está ligada à mentira, vinha dessa extrema-direita, que correspondia a cerca de 10\%, no máximo $15 \%$ dos participantes nas manifestações em prol do impeachment da presidente. Embora proporcionalmente em menor número, eles, no entanto, eram aqueles que produziam a radicalidade extremada, que fomentavam as fantasias de crise da civilização e de iminência de uma destruição da sociedade. Foi essa fantasia, essa 'energia', que foi transmitida para todo o movimento. Então eles tiveram uma função muito importante: a função de radicalizar e de informar o radicalismo do movimento da 'nova 
direita'. Esse radicalismo não foi movido pelos liberais que estavam interessados no processo. Ele foi movido pela paixão popular, porque essas pessoas são populares.

Em um segundo momento, essas pessoas forneceram o lastro de legitimidade do movimento, não aquele que visavam por meio da adesão do Exército, que se recusou a ocupar esse papel que eles idealizavam, desejavam. Esse simples 'desencontro' mostra a perspectiva totalmente distorcida que foi adotada por esses membros da extrema-direita em relação à História contemporânea. Eles não são capazes de pensá-la ou de pensar a partir dela. Eles pensam um transcendente a essa História, um não mais aqui, uma vez que eles ainda estão presos em um passado e correm atrás de um anticomunismo de tipo Guerra Fria, que não se sustenta se considerada a História contemporânea.

A esquerda não é uma esquerda comunista, como afirmam. É uma esquerda democrática, a ponto de ter sido processada na Democracia e ter aceitado o processo, diferentemente do que eles dizem. Aliás, nada do que eles dizem corresponde às práticas reais da esquerda. No entanto, eles conseguiram impor essa visão distorcida e destrutiva, evidentemente não porque eles são competentes, fortes, inteligentes, mas porque o que faziam servia a um movimento mais amplo, mais potente, o movimento do 'capital' contemporâneo.

É disso que advém o lastro, não de verdade, mas de legitimidade de que dispõem. Não se trata de um lastro com base na verdade, porque não há verdade no que dizem. Isso, no entanto, importa menos para o status quo do capital, que se fez de indiferente frente ao que diziam, faziam e se tornavam. Não importa, desde que os interesses do capital estejam satisfeitos. Foi esse mesmo lastro que permitiu figuras como Bolsonaro circularem na política nacional. O que lastreia o Bolsonaro não é nenhuma inteligência especial, não é nenhuma verdade, nenhuma habilidade no mundo político, e todo mundo sabe disso. Isso não vem ao caso. O Bolsonaro é meramente uma das saídas possíveis de uma crise para o capital, é uma resposta política possível a favor do capital. Para o capital se blindar totalmente em uma crise, não há nenhum impedimento ético em rachar a relação estado-capital-sociedade. O capital não tem escrúpulos em seguir seu caminho ao lado do fascista. Sua eleição é uma das possibilidades para o capital, embora não seja para a sociedade. Para o capital, o raciocínio é simples: a sociedade que pague esse preço.

Então, diante da recusa do Exército a assumir novamente esse papel, essas pessoas que originalmente eram intervencionistas se deslocaram para o bolsonarismo, embora não fosse o Bolsonaro aquilo que elas de fato queriam. Nesse momento, Bolsonaro herdou essa mobilização fracassada, que não conseguiu o que queria. Essas pessoas engajam-se no autoritarismo porque, como podemos perceber vendo o nosso documentário, e o que dizem 
essas pessoas, Bolsonaro é como elas e elas são como um Bolsonaro. Eles não são diferentes. Ambos são degradados, mal informados, mal formados, delirantes e autoritários. Eles têm um déficit de conhecimento satisfeito e têm um engajamento no próprio desejo que, do ponto de vista da fantasia, lhes outorga o direito de passar ao ato, porque se creem estarem salvando o mundo. 'Passar ao ato', ou seja, 'partir para a porrada', partir para a violência, fazer a política do ódio e da violência é necessário em nome do que acreditam estarem fazendo: eles se imaginam salvando o mundo do Comunismo - que não existe -, mas isso não vem ao caso. Para eles esse detalhe não importa. Trata-se de um gesto de onipotência psíquica política.

Nesse sentido, são todos iguais. Eles todos têm essa mesma estrutura: todos são ignorantes e voluntaristas, todos estão em um processo de salvacionismo, todos acreditam na ação de violência, na política de violência real. O Bolsonaro não é uma liderança superior, é uma liderança de tipo fraterna, ou seja, é como se fosse um deles qualquer. Ele faz parte do baixo-clero do exército de torturadores da década de setenta, algo de que o Exército tentou relativamente se afastar, abafar e deixar no esquecimento. Essas pessoas, porém, não deixam isso acontecer, porque imaginam que são elas que serão perseguidas, que estão correndo risco o tempo todo de serem cobradas quanto a isso que fizeram, já que, se houver uma cobrança histórica efetiva, seriam justamente elas que pagariam, já que foram elas que torturaram, mataram e desapareceram com cidadãos. São elas que estão na "chapa quente" da persecutoriedade que a própria Democracia exerce sobre elas. Portanto, esse grupo teve duas funções: a de transferir energia para o movimento geral da direita, e depois a de lastrear, sustentar um movimento político próprio, via o candidato fascista, rebaixado, ex-oficial de baixa patente, protetor de ditador, Jair Bolsonaro.

\section{Referências}

BENJAMIN, Walter. Teses sobre o Conceito da História. Tradução Sérgio Paulo Rouanet. In: Walter Benjamin - Obras Escolhidas I, Magia e Técnica, Arte e Política. Ensaios sobre Literatura e História da Cultura. São Paulo: Brasiliense, 1987, p. 232-282.

FREUD, Sigmund. O mal-estar na civilização: novas conferências introdutórias e outros textos (1930-1936). São Paulo: Companhia das Letras, 2010.

FREUD, Sigmund. Psicologia das massas e análise do eu e outros textos (1920-1923). São Paulo: Companhia das Letras, 2011. 
FREUD, Sigmund. Inibição, Sintoma e Angústia. O futuro de uma ilusão e outros textos (1926-1929). São Paulo: Companhia das Letras, 2014.

WEBER, Max. Os três tipos de dominação legítima. In: Economia e Sociedade: Fundamentos da Sociologia compreensiva. Brasília: Editora da UnB, 1999.

Recebido em: 12 de fevereiro de 2020.

Aceito em: 17 de abril de 2020. 